\title{
CORRECTION
}

\section{Correction to: Butanol and butyric acid production from Saccharina japonica by Clostridium acetobutylicum and Clostridium tyrobutyricum with adaptive evolution}

\author{
Chae Hun $\mathrm{Ra}^{1} \cdot$ In Yung Sunwoo ${ }^{2} \cdot$ Trung Hau Nguyen $^{2} \cdot$ Pailin Sukwong $^{2} \cdot$ Phunlap Sirisuk $^{2} \cdot$ Gwi-Taek Jeong ${ }^{2} \cdot$ \\ Sung-Koo Kim ${ }^{2}$
}

Published online: 20 May 2019

(c) Springer-Verlag GmbH Germany, part of Springer Nature 2019

\section{Correction to: \\ Bioprocess and Biosystems Engineering \\ (2019) 42:583-592 \\ https://doi.org/10.1007/s00449-018-02063-9}

Unfortunately, the author name was wrongly published as Pailin Sukwang instead of Pailin Sukwong.

Publisher's Note Springer Nature remains neutral with regard to jurisdictional claims in published maps and institutional affiliations.

The original article can be found online at https://doi.org/10.1007/ s00449-018-02063-9.

Sung-Koo Kim

skkim@pknu.ac.kr

1 Department of Food Science and Biotechnology, Food and Bio-industry Research Center, Hankyong National University, Anseong 17579, South Korea

2 Department of Biotechnology, Pukyong National University, Busan 48513, South Korea 